\title{
Dynamic soil properties of some deep trenches in Mashhad city, NE Iran
}

\author{
Azam Ghazi*, Naser Hafezi Moghadas, Hossein Sadeghi, \\ Mohammad Ghafoori and Gholam Reza Lashkaripour \\ Department of Geology, Faculty of Sciences, Ferdowsi University of Mashhad, Mashhad, Iran. \\ ${ }^{*}$ Corresponding author.e-mail: azam.ghazi@stu-mail.um.ac.ir
}

Microtremor survey is achieved in order to evaluate the dynamical characteristics of surface layers. For this purpose, 13 trenches were selected and microtremor measurements were performed at the top and bottom of each trench. Floor spectral ratio (FRS) analysis was accomplished to obtain frequency and amplification of the trenches. The results of microtremor were compared with 1D equivalent linear analysis. Most of the fundamental frequencies obtained by 1D analysis are in good agreement with those calculated by microtremor technique. Irregularities in surface and subsurface geomorphic conditions tend to have differences in results obtained by both mentioned methods. Damping ratios were derived from the half power bandwidth method. The damping ratio varied between 2.1 in fine grain soils and 6.6 in sand soils.

\section{Introduction}

Surface geological conditions have significant effects on amplification and deamplification of strong ground motion at special frequencies (Borcherdt 1970; Joyner and Boore 1988; Zeng 1993; Olsen and Archuleta 1996; Woolery and Street 2002; Apostolidis et al. 2004; Nguyen et al. 2004; Teramo et al. 2005; Hasancebi and Ulusay 2006; Leyton et al. 2013). Past earthquakes such as the 1985 Mexico city (Mexico), the 1990 Manjil-rudbar earthquake (Iran), the 1994 Northridge earthquake (Los Angeles), the 1995 Kobe earthquake (Japan), the 1999 Izmir earthquake (Turkey) and the 2003 Bam earthquake (Iran) are evidences for local geology and soil deposit effects on ground motions and distribution of damages in metropolitan areas (Singh et al. 1988; Somerville and Graves 1996; Tertulliani 2000; Bakir et al. 2002; Jafari et al. 2005; Rezaei et al. 2012).
Microtremor measurement is one of the important methods to evaluate the seismic site response, which is widely used in the urban areas because of its quick and easy performance at low cost with minimum disturbance (Walling et al. 2009). Theory and practical application of the microtremors were introduced by Kanai and Tanaka (1954) and were popularized by Nakamura (1989, 2000), who introduced horizontal-vertical spectral ratio (HVSR). This method is used to determine dynamic properties of the soil deposits like predominant frequency, amplification, and damping ratio, and to evaluate the thickness of the alluvial deposits (Kanai and Tanaka 1961; Field and Jacob 1993; Lermo and Chavez-Garcia 1994; Ohmachi et al. 1994; Ibs-von Seht and Wohlenberg 1999; Luzón et al. 2001; Xun et al. 2002). The amplification estimated from the mentioned method is lower than that estimated from earthquake recording. However, some researchers have mentioned that

Keywords. Microtremor; damping ratio; natural frequency; Mashhad city; 1D equivalent linear. 


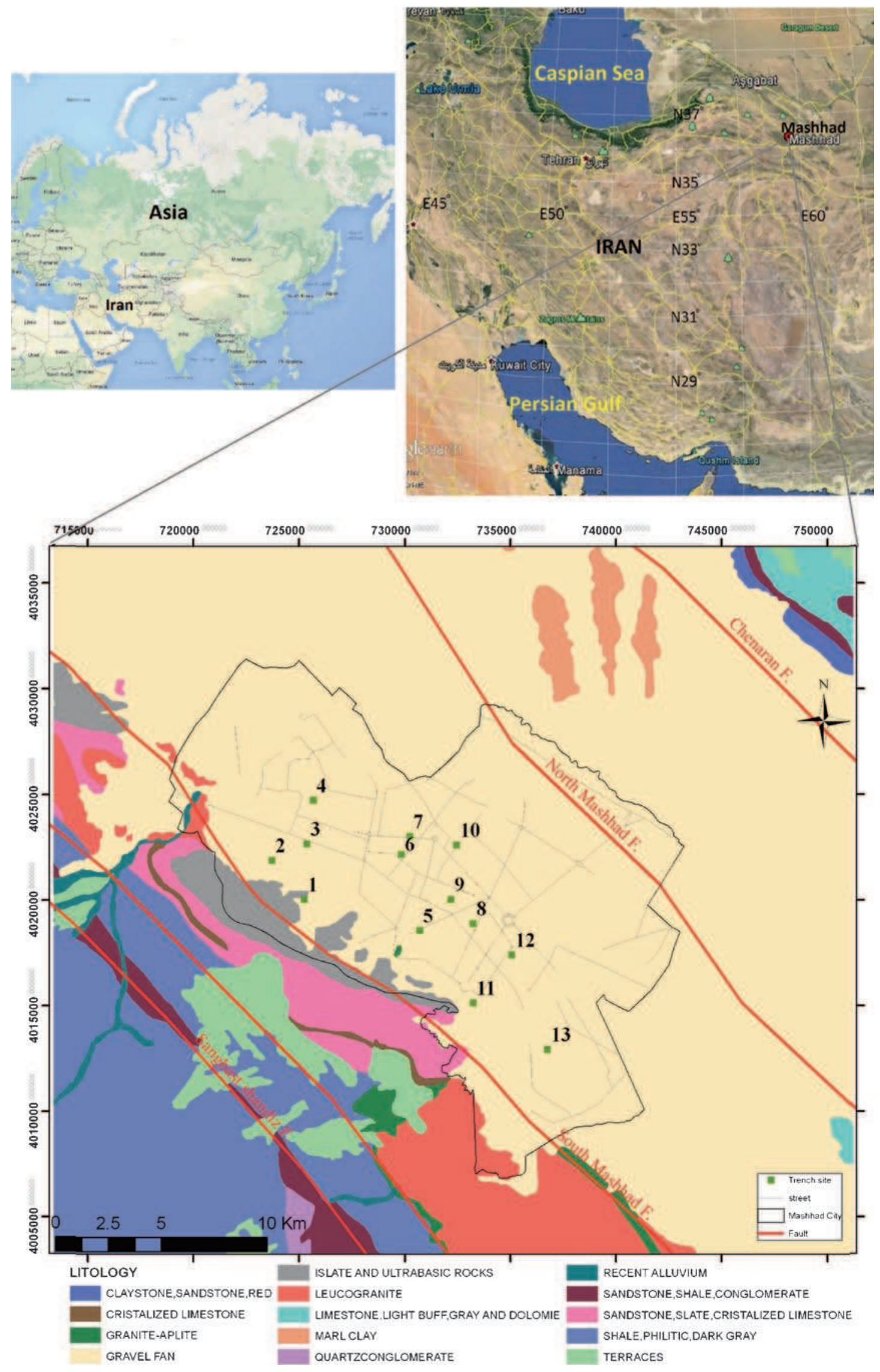

Figure 1. Location of the study area and trench sites discussed. Trench sites are showed with green rectangles and determined by code. 
it is unreliable amplification (Singh et al. 2014) and we can use it as lower limit of amplification for Mashhad city.

In this study, we used single HVSR method to evaluate the dynamic properties of the soils in some of the deep trenches in Mashhad metropolitan city. The spiritual capital city of Mashhad is located in the northeast of Iran as seen in figure 1. The city has about 2.5 million permanent residents and has more than 20 million visitors and pilgrims annually. The city is surrounded by some active faults and is built over thick alluvial deposits.

\section{Materials and methods}

\subsection{Geological setting}

The capital city of Mashhad with an area of $300 \mathrm{~km}^{2}$ is located in the east end of Mashhad plain. Mashhad plain is a Graben formed between two main tectonic zones of Bilaloud in north and Kopet-Dagh in south. Thick fans and alluvial deposits cover the Mashhad city area. Thickness of the deposits increases towards the east and central parts and reaches up to more than $350 \mathrm{~m}$.
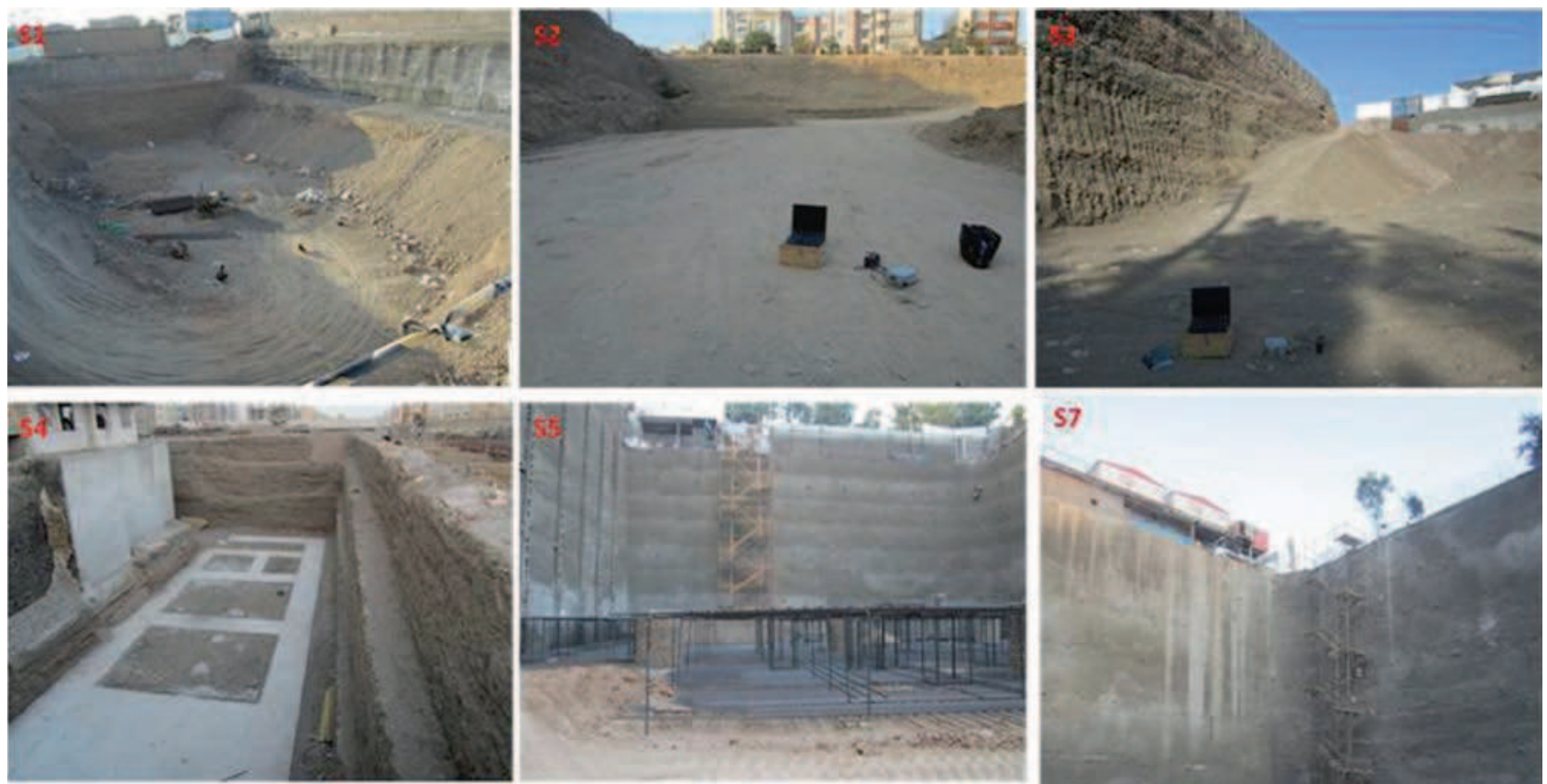

$\$ 7$
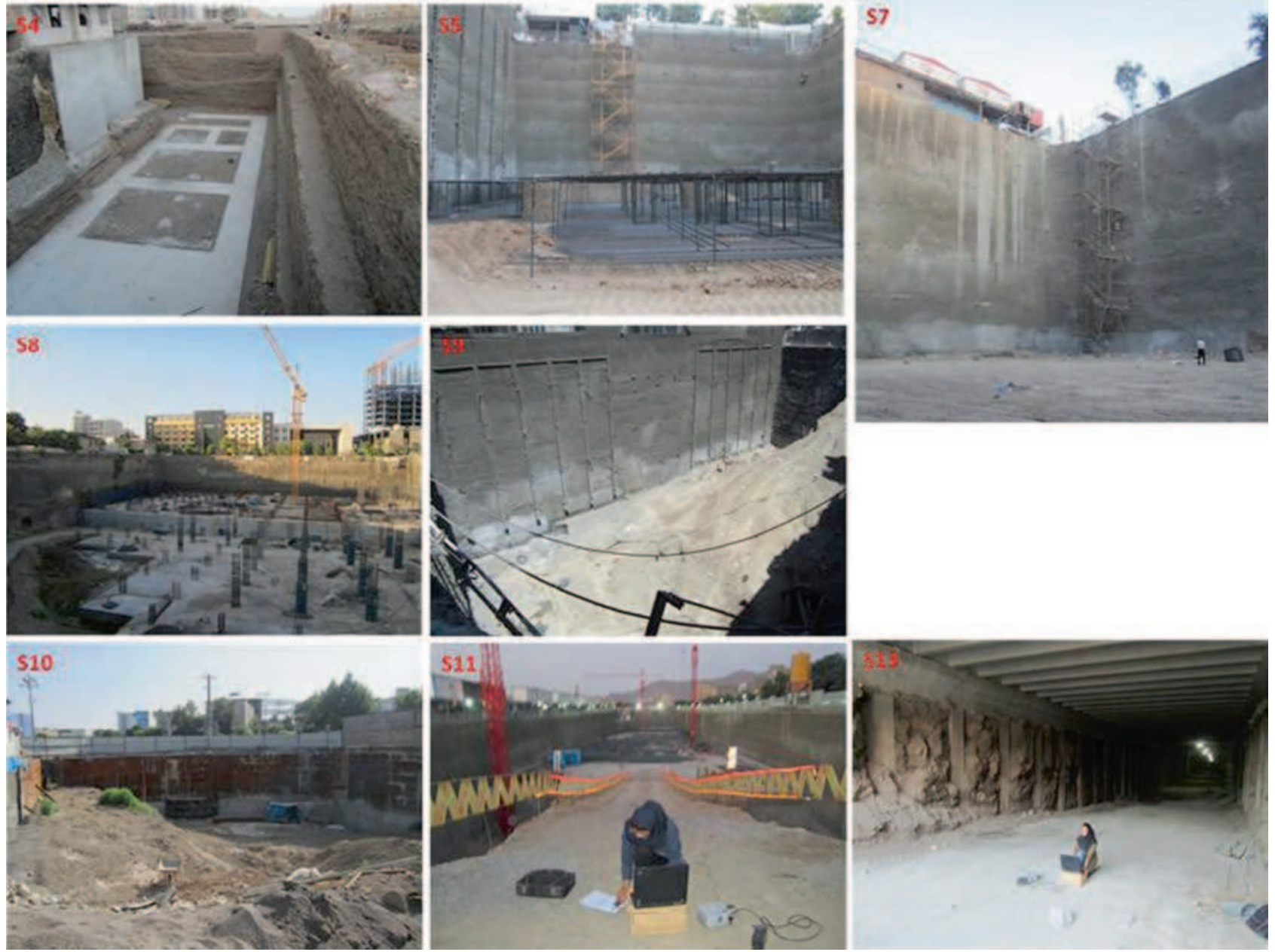

Figure 2. View of trenches and measurement surveys. Measurements were done with SL07 seismometer which was placed on the open ground at the top and bottom of trenches. 
For this study, 13 deep trenches at different site locations of the city, where geotechnical and geophysical studies were performed, were selected. Depth of the trenches ranges from 10 up to $22 \mathrm{~m}$. Trenches and measurement surveys are shown in figure 2. Predominant soil textures at the locations of site nos. 1-7, 9 and 13 include sand and gravel, while silt and clay are predominant soils at the locations of site nos. 8, 10, 11 and 12. Depositional condition at the locations of site nos. $5,8,11$ and 12 change frequently, and the profiles are composed of alternate layers of coarse and fine-grained soils. The soil texture and shear wave velocity profiles are shown in figure 3 . The shear wave velocity (Vs) was measured by seismic downhole method at $2 \mathrm{~m}$ depth interval at each borehole. The Vs increases gradually with depth, and reaches to 800 $\mathrm{m} / \mathrm{s}$ at site nos. 1,2 and 6 and $600 \mathrm{~m} / \mathrm{s}$ for other sites at the depth of $30 \mathrm{~m}$. The mean Vs up to $30 \mathrm{~m}$ (Vs30) and the mean Vs of the trenched layer
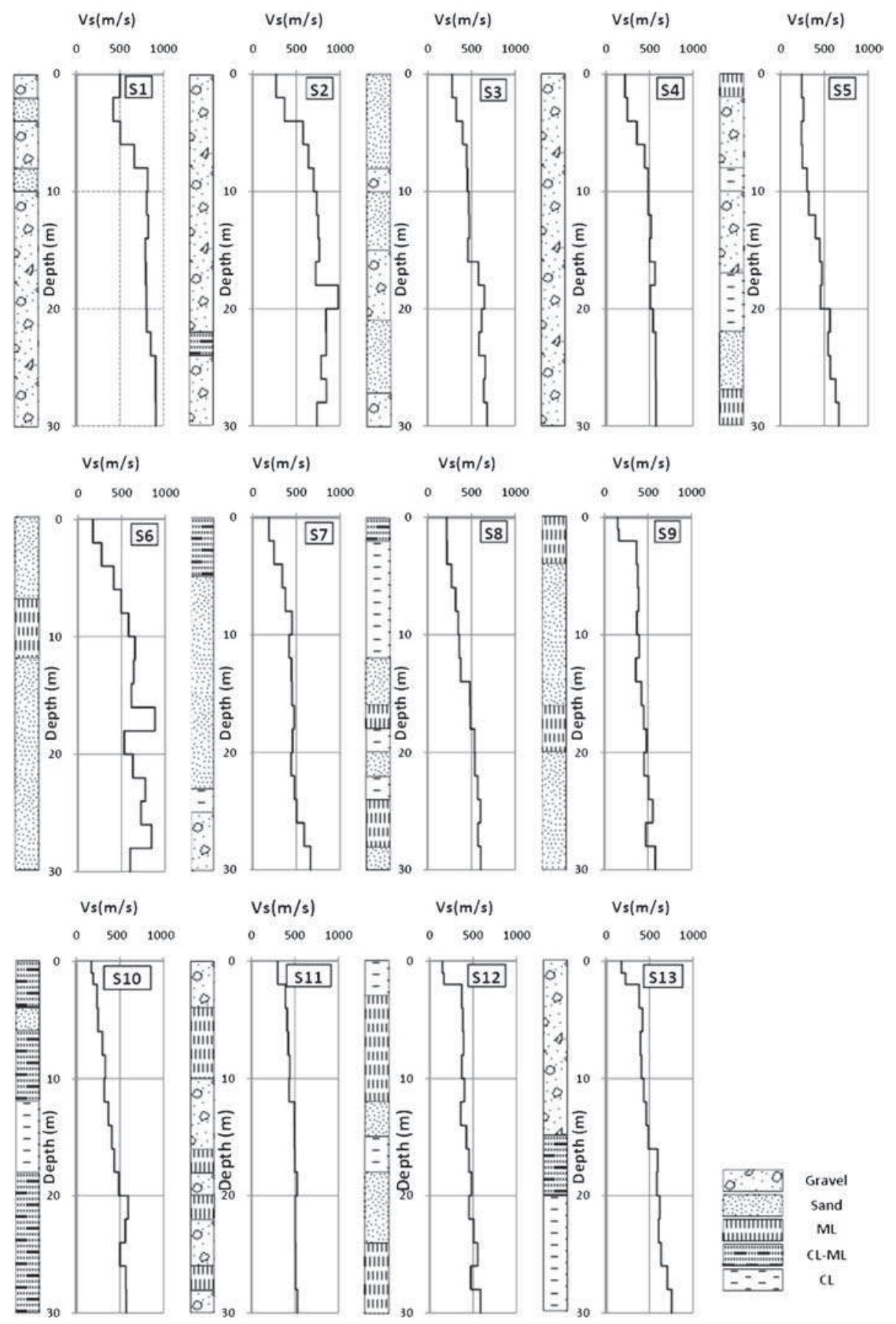

Figure 3. Soil texture and shear wave velocity profiles at each of the 13 study sites, illustrating the subsurface ground condition at Mashhad city. ML, CL and CL-ML are the unified symbols for silts, clays, silty clays, respectively. 
Table 1. Characteristics of soil layers of studied wall trenches.

\begin{tabular}{|c|c|c|c|c|c|}
\hline $\begin{array}{l}\text { Site } \\
\text { no. }\end{array}$ & Soil type & $\begin{array}{l}\mathrm{D}_{\mathrm{T}} \\
(\mathrm{m})\end{array}$ & $\begin{array}{c}\mathrm{H}_{\text {total }} \\
(\mathrm{m})\end{array}$ & $\begin{array}{l}\mathrm{Vs}_{30} \\
(\mathrm{~m} / \mathrm{s})\end{array}$ & $\begin{array}{l}\mathrm{Vs}_{\mathrm{T}} \\
(\mathrm{m} / \mathrm{s})\end{array}$ \\
\hline 1 & Gravel & 11.6 & 30 & 715 & 583 \\
\hline 2 & Gravel & 10 & 50 & 629 & 446 \\
\hline 3 & Sand & 10.5 & 230 & 481 & 365 \\
\hline 4 & Gravel & 10.6 & 280 & 436 & 326 \\
\hline 5 & Gravel & 19 & 180 & 544 & 467 \\
\hline 6 & Sand & 22 & 275 & 491 & 439 \\
\hline 7 & Sand & 22 & 300 & 394 & 356 \\
\hline 8 & Fine grained & 19 & 235 & 384 & 322 \\
\hline 9 & Sand & 18 & 250 & 405 & 350 \\
\hline 10 & Fine grained & 9 & 320 & 361 & 244 \\
\hline 11 & Fine grained & 20 & 75 & 456 & 432 \\
\hline 12 & Fine grained & 22 & 210 & 388 & 354 \\
\hline 13 & Gravel & 8 & 170 & 461 & 318 \\
\hline
\end{tabular}

$\mathrm{D}_{\mathrm{T}}$ : trench depth, $\mathrm{H}_{\text {total }}$ : thickness of alluvium deposits.

(VsT) were computed by using the time averaged equation as follows:

$$
\bar{V}_{s}=\frac{H}{\sum_{i=1}^{n}\left(h_{i} / V_{s i}\right)} .
$$

The results as well as thickness of alluvium $\left(\mathrm{H}_{\text {total }}\right)$ and trench depth $\left(\mathrm{D}_{\mathrm{T}}\right)$ are presented in table 1 . The alluvium thickness ranges between 30 and $300 \mathrm{~m}$ at the location of sites.

\subsection{Methodology}

The HVSR method of free field microtremor was applied to assess the dynamic properties of the 13 trenched layers in Mashhad capital city in northeast of Iran. Microtremor data are obtained by SARA 3-component seismometer model SL07 with a $2 \mathrm{~Hz}$ natural frequency, the frequency response of $0.5-20 \mathrm{~Hz}$ and the critical damping equal to 0.7. Data measurements were done at the top and bottom of all trenches. The measurements were done at early mornings or at the evenings, in order to avoid adverse effects of man-made noise and heavy machinery activities. The sampling frequency was $100 \mathrm{~Hz}$ and the recording length was $15 \mathrm{~min}$ at each survey. The HVSR analyses were performed by Geopsy software (www.geopsy.org) in the following way. Each record was split into 15-25 s non-overlapping windows. Bandpass filter in the range of $0.2-20 \mathrm{~Hz}$, linear Butterworth filter and $5 \%$ cosine tapper on both sides of the windows were applied in order to eliminate intensive noise. Then, Fast Fourier Transform (FFT) was computed and Fourier spectra were smoothed by Konno and Ohmachi function in a logarithmic scale to clarify the curves (Konno and Ohmachi 1998). Finally, the average curve of $\mathrm{H} / \mathrm{V}$ was computed.
Furthermore, floor spectral ratio (FSR) proposed by Gosar et al. (2010) was used to determine the dynamical properties of the wall trench soils. FSR estimates transfer function of the structure by ratio of spectra of structure to spectra of ground. In this method, for both horizontal components, average spectra were computed for each floor and the ratio of spectra between the floors and the basement was computed. For both measurements, the length of the records must be equal; however, it is not necessary to do simultaneously. The authors use this idea to estimate transfer function of the trench wall (Gosar et al. 2010). Transfer functions of the trenched layer are estimated by the ratio of spectral of top to spectral of bottom of the trench. In addition, the damping ratios of the trenched layers were evaluated using the half power bandwidth method.

In half power bandwidth method, the frequency width of FSR curve was determined at the peak amplitude of 0.707 times, and then the damping ratio was computed by using the following equation (Xun et al. 2002):

$$
\xi=\frac{\Delta f}{f_{0}}
$$

where $\Delta f\left(=f_{2}-f_{1}\right)$ is the frequency width and $f_{0}$ is the peak frequency of the spectrum as observed in figure 4 . The obtained damping ratio must be calibrated by calibration coefficient of 5.32 because of smoothing operations. The smoothing causes the damping to become enlarged (Xun et al. 2002).

In addition, the transfer functions of trenched layers are estimated by one dimension equivalent linear method using the Proshake software (EduPro Civil System, Inc. 1998).

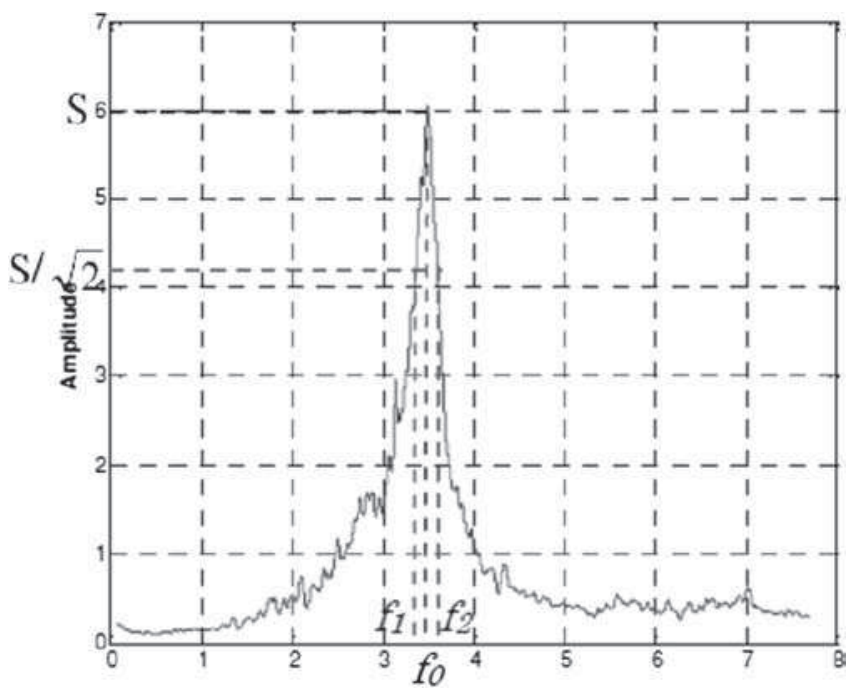

Figure 4. Estimating of damping by half power bandwidth method. $S$ is amplitude of peak frequency $\left(f_{0}\right) . f_{1}$ and $f_{2}$ are frequencies at amplitude of $S / \sqrt{2}$. 


\section{Results and discussion}

The HVSR curves at the top and bottom of the trenches are shown in figure 5. Most of the curves fulfill the criteria for reliable measurements and a clear peak (SESAME 2004). Fundamental frequency reflects the thickness of soft sediment, while clarity and amplitude of the peak are related to the Vs contrast between the upper soft sediment and the seismic bedrock. Higher contrast results in
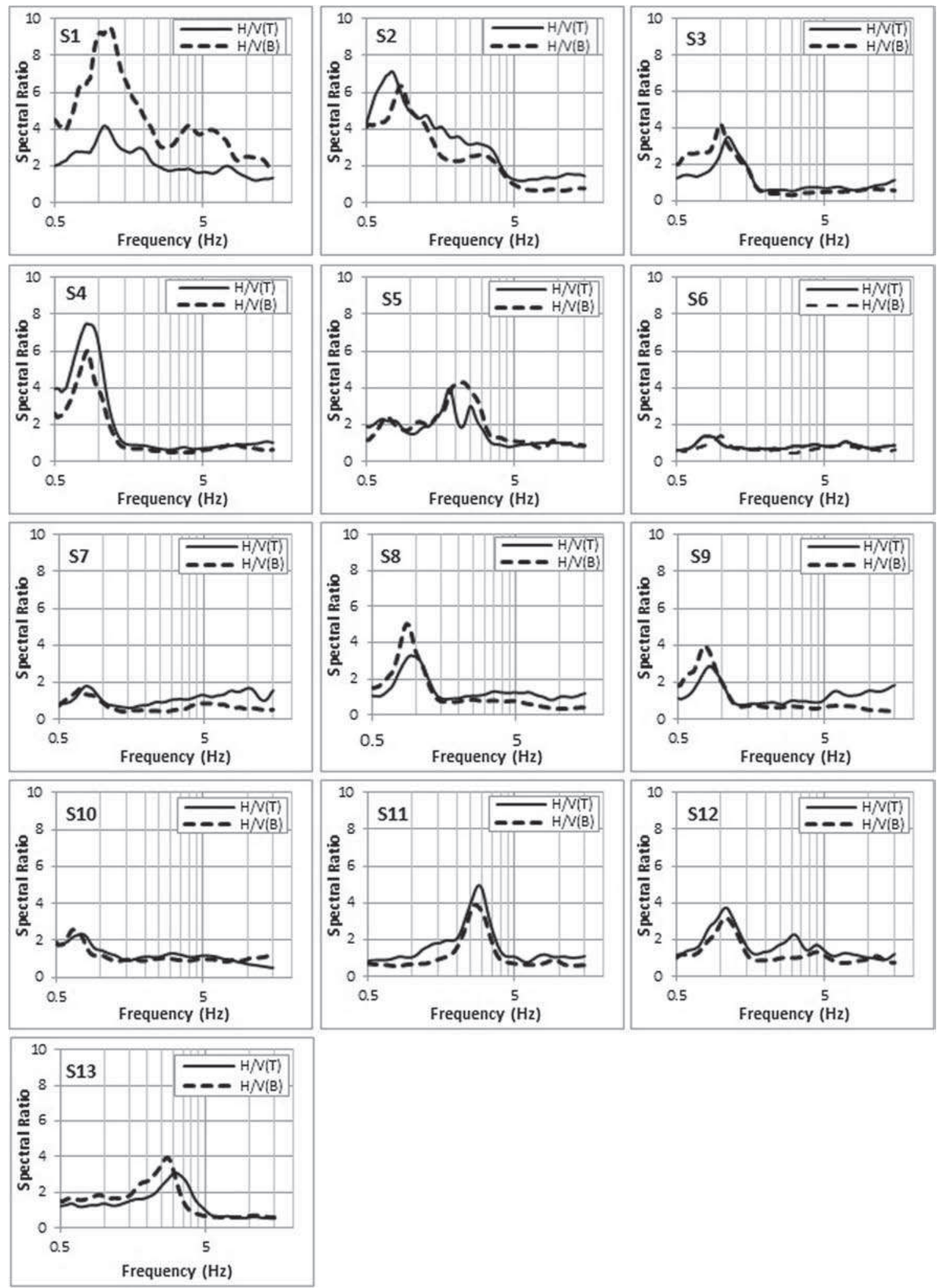

Figure 5. HVSR curves of trench bottom compared with those of ground surface. Solid lines show the HVSR curves at the ground surfaces and dashed lines show the HVSR curves at the bottom of trenches. 
higher amplitude (Field and Jacob 1993; Tokeshi and Sugimura 1998).

The fundamental frequency of surface values fall in the range of $0.73-3.3 \mathrm{~Hz}$. For the fundamental frequency of HVSR, the city could be divided into two parts based on the site's distance from south mountains. The sites S1-S3, S5, S11-S13, which are situated near the mountains, with distance $<2500 \mathrm{~m}$, have a fundamental frequency $>1 \mathrm{~Hz}$ with an exception of site no. 2. The sites which are far from the mountains have a fundamental frequency $<1 \mathrm{~Hz}$. As observed from figure 1, the soft sediments become progressively thicker with increasing distance from the south mountains. The thicknesses of soft sediments vary between 235 and $320 \mathrm{~m}$ and fundamental frequencies range from 0.73 to $0.92 \mathrm{~Hz}$ at locations $\mathrm{S} 4, \mathrm{~S} 6-\mathrm{S} 10$. The red line in figure 6 indicates the dividing line. The dividing line approximately corresponds to thickness of $230 \mathrm{~m}$. There is relation between thickness and fundamental frequency but evaluation of correlation between them is impossible because of limited data. Amplitude values of fundamental frequency of surface HVSR curves could be divided into three groups of $<2$ (I), 2-4 (II) and >4 (III). The sites S6, S7 and
S10, which are located at the central part of the city with thick alluvium and marl bedrock (Azadi et al. 2009), are classified as group I. The sites S1, $\mathrm{S} 2, \mathrm{~S} 4$ and S11 are categorized as group III. The sites S1, S2 also have wide peaks. It implies that the overlain schist behaves as seismic bedrock. The site S11 is close to mountain with overlain ultrabasic bedrock. Other sites are categorized as group II. At the locations of sites S8, S9 and S12, the soft sediments are composed of sand, silt and clay and are almost $230 \mathrm{~m}$ thick. Three sites of S3, S5 and S13, with the same amplitude of fundamental frequency, have similar condition. The profiles of soft sediments are composed of coarse grain soils with a clay lens approximately $15 \mathrm{~m}$ thick at the depth of 15-30 m (S5 and S13) and 45-60 m (S3).

Comparison of the spectral curves at the top and bottom of the trenches shows that there are no significant difference between fundamental frequency values at the bottom and top of the sites S4, S6S10 which are underlain by thicker soft sediments. At locations of these sites, ratios of trench depth to total soft sediment thickness are small. The amplitudes of fundamental frequency at the bottom of trenches are also evaluated. The HVSR curves at

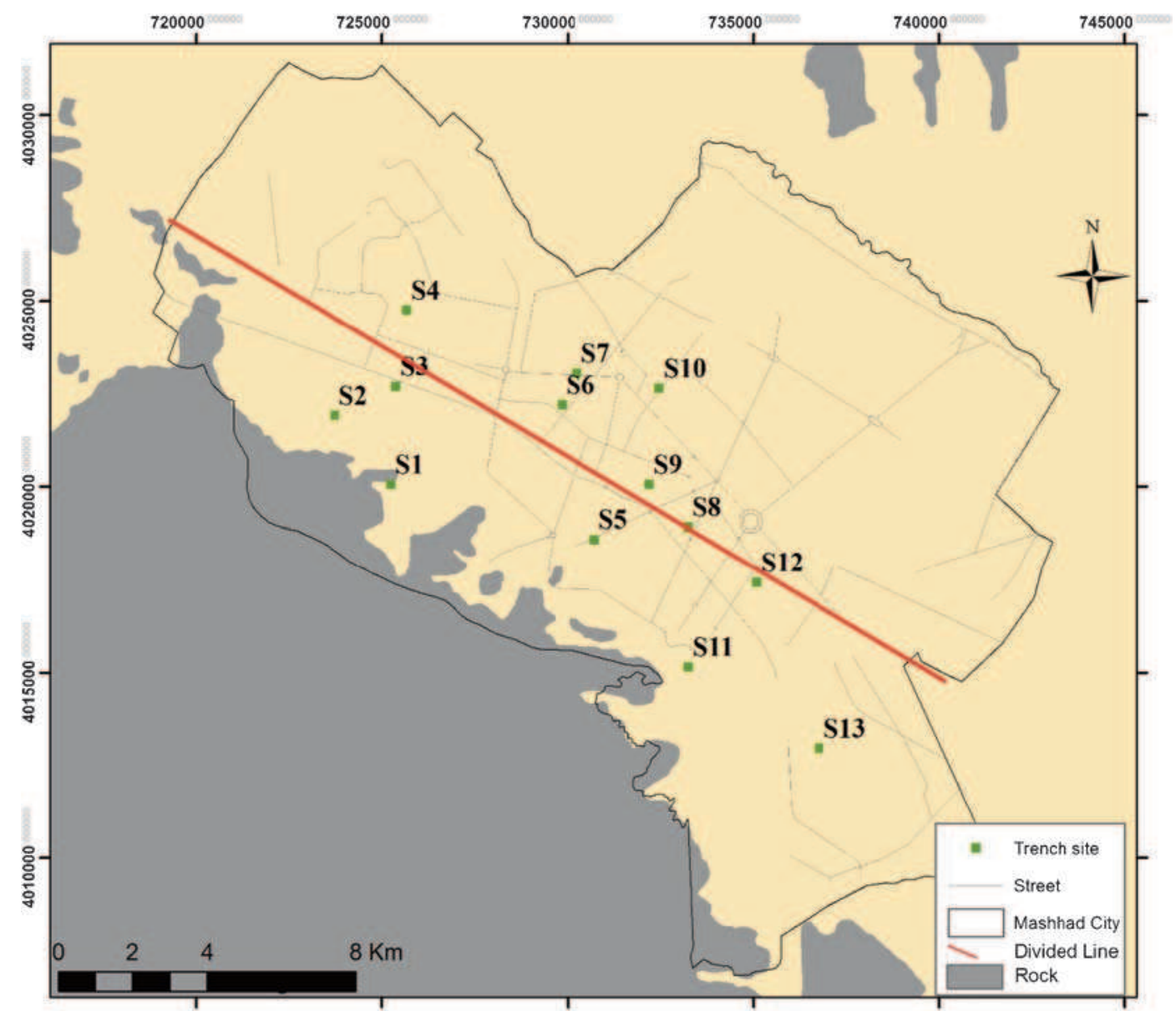

Figure 6. Situation of trenches relative to the dividing line which separate the areas with fundamental frequency more than $1 \mathrm{~Hz}$ from areas with fundamental frequency less than $1 \mathrm{~Hz}$. The dividing line is shown by the red line. 

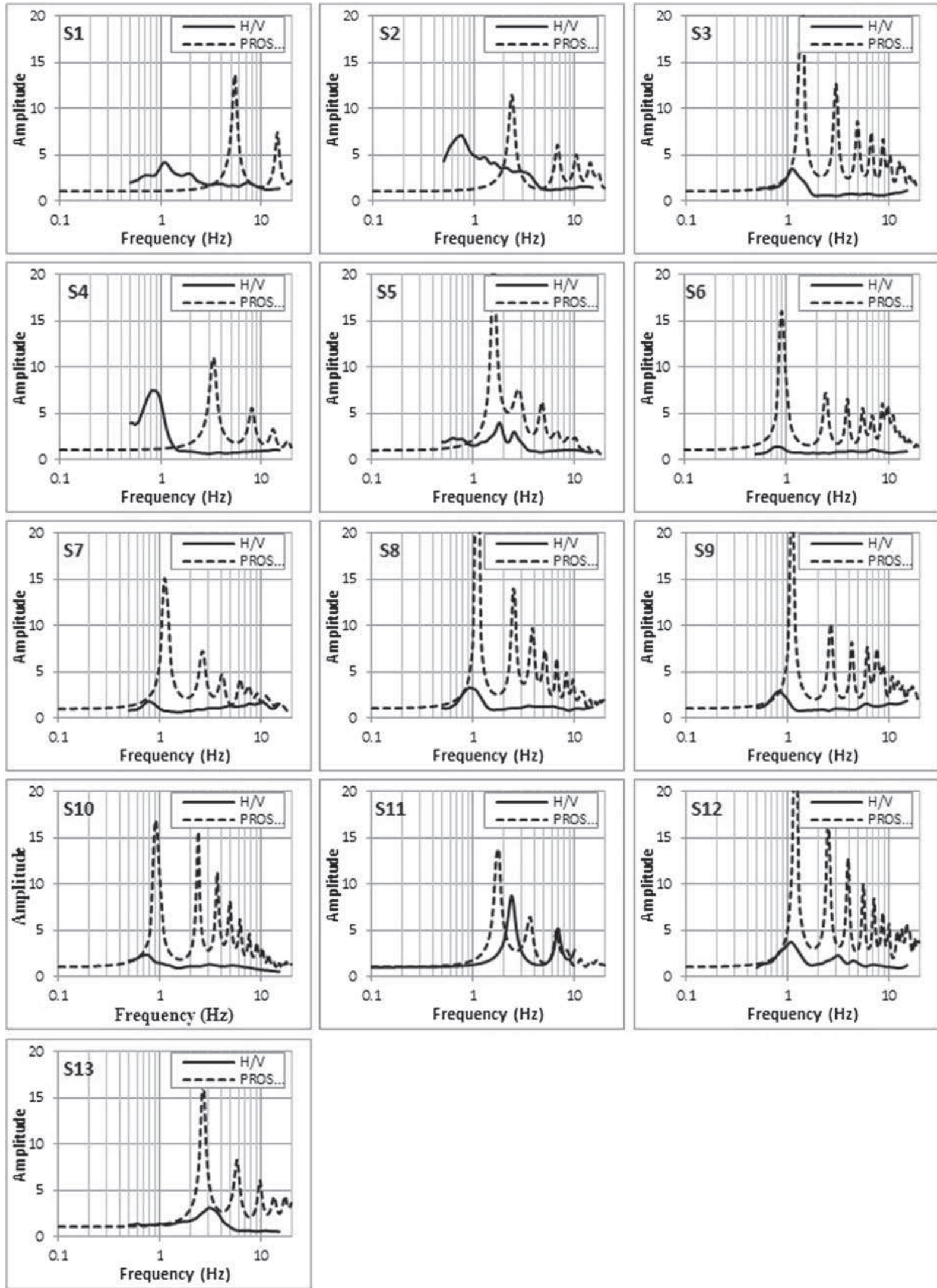

Figure 7. Comparison of transfer functions of total soil profiles using 1D equivalent linear and HVSR methods at the ground surface. Solid lines show the HVSR (H/V) curves and dashed lines show the transfer function curves obtained by Proshake (1D equivalent linear analysis). 

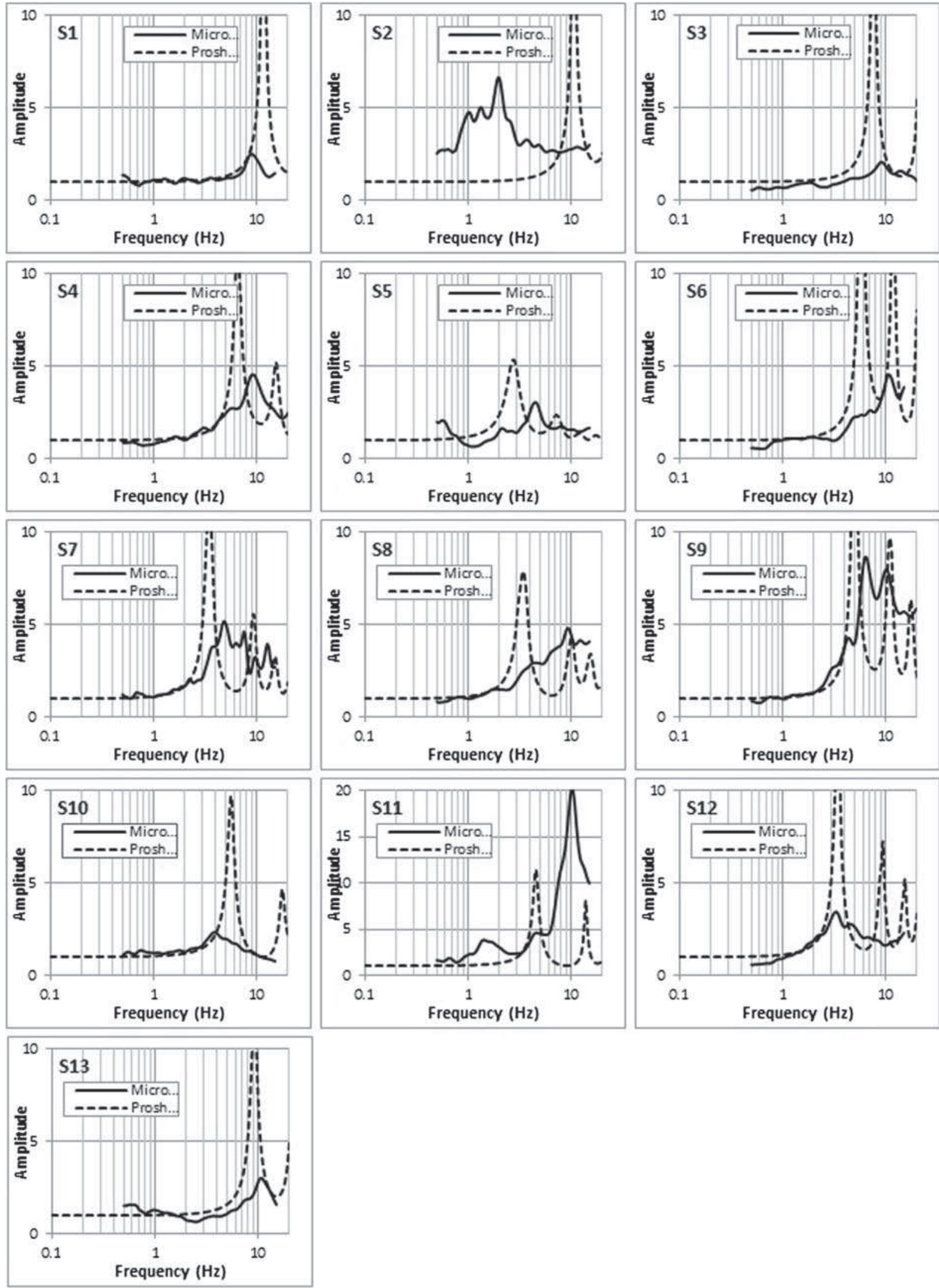

Figure 8. Comparison of transfer functions of trench wall using 1D equivalent linear and HVSR methods. Solid lines show the HVSR $(\mathrm{H} / \mathrm{V})$ curves and dashed lines show the transfer function curves obtained by Proshake. 
the bottom of the sites $\mathrm{S} 1, \mathrm{~S} 2$ and $\mathrm{S} 4$ show the fundamental frequency amplitude of more than 4, similar to the surface curves. The HVSR curve at the bottom of site S1 is very clear and sharper, and also shows higher amplitude at fundamental frequency rather than the HVSR curve at the top of site. The site S1 is very close to mountain and is composed of large rock fragments to fine grain. The amplitude values of fundamental frequency at the bottom and top of the sites S6, S7 and S10 are similar. The amplitude values of fundamental frequency become more at the bottom of the sites S8 and S9 where groundwater level is located at a depth of $40 \mathrm{~m}$. The sites S3, S5 and S13 also show higher amplitude values of fundamental frequency at the bottom, and removing coarse grain layer could be the reason.

The HVSR curves of the surface and transfer functions of $1 \mathrm{D}$ equivalent linear are compared in figure 7 . The profiles to the bedrock were used for the $1 \mathrm{D}$ equivalent linear analysis and the $\mathrm{Vs}$ of deep parts were estimated based on the previous studies (Hafezi Moghadas et al. 2007). The shear modulus reduction and damping ratio curves proposed by Seed and Idriss (1970), Seed et al. (1986) and Idriss (1990) were used for sand, gravel and rock, respectively. The shear modulus reduction curves suggested by Seed and Sun (1989) and Sun et al. (1988) and damping ratio curves suggested by Idriss (1990) and Sun et al. (1988) were used for soft clays based on PI values. 1D equivalent linear analysis resulted in higher amplitude of fundamental frequency rather than HVSR analysis. Komak Panah et al. (2002) noted that HVSR technique results in the underestimation of amplitude of fundamental frequency. As observed in figure 7, there are clear differences between HVSR and Proshake fundamental frequencies for the sites S1, S2 and S4, while the best matching between two techniques is observed at the site S12. The sites S1 and S2 are located near the mountains with faulting edge and irregular bedrock, which cannot be modelled

Table 2. The results of HVSR and $1 D$ equivalent linear techniques at top and bottom of the trenches.

\begin{tabular}{llllcccccccc}
\hline $\begin{array}{l}\text { Site } \\
\text { no. }\end{array}$ & $\begin{array}{c}\mathrm{F}_{\mathrm{M}-\mathrm{t}} \\
(\mathrm{Hz})\end{array}$ & $\begin{array}{c}\mathrm{F}_{\mathrm{M}-\mathrm{b}} \\
(\mathrm{Hz})\end{array}$ & $\begin{array}{c}\mathrm{F}_{1 \mathrm{D}-\mathrm{t}} \\
(\mathrm{Hz})\end{array}$ & $\begin{array}{c}\mathrm{F}_{\mathrm{M}-\mathrm{T}} \\
(\mathrm{Hz})\end{array}$ & $\begin{array}{c}\mathrm{F}_{1 \mathrm{D}-\mathrm{T}} \\
(\mathrm{Hz})\end{array}$ & $\mathrm{A}_{\mathrm{M}-\mathrm{t}}$ & $\mathrm{A}_{\mathrm{M}-\mathrm{b}}$ & $\mathrm{A}_{1 \mathrm{D}-\mathrm{t}}$ & $\mathrm{A}_{\mathrm{M}-\mathrm{T}}$ & $\mathrm{A}_{1 \mathrm{D}-\mathrm{T}}$ & $\begin{array}{c}\xi_{\tau} \\
(\%)\end{array}$ \\
\hline 1 & 1.1 & 1.18 & 5.5 & 9 & 11.6 & 4.10 & 9.40 & 14 & 2.5 & 18 & 3.9 \\
2 & 0.75 & 0.87 & 2.4 & 2 & 10.5 & 7.06 & 6.1 & 11 & 6.6 & 16 & 3.8 \\
3 & 1.123 & 1.001 & 1.4 & 8.9 & 7.6 & 3.73 & 5.17 & 23 & 2.1 & 17 & 2.8 \\
4 & 0.84 & 0.84 & 3.3 & 9.3 & 6.5 & 6.54 & 5.8 & 11 & 4.5 & 11 & 5.4 \\
5 & 1.83 & 2.29 & 1.6 & 4.5 & 2.7 & 3.87 & 4.22 & 23 & 3.1 & 5 & 2.6 \\
6 & 0.73 & 0.963 & 0.9 & 10.6 & 5.8 & 1.41 & 1.38 & 16 & 4.5 & 29 & 6.6 \\
7 & 0.785 & 0.708 & 1.1 & 4.8 & 3.4 & 1.80 & 1.80 & 15 & 5.2 & 11 & 3.2 \\
8 & 0.93 & 0.867 & 1.1 & 9.3 & 3.4 & 3.27 & 4.96 & 37 & 4.8 & 8 & \\
9 & 0.82 & 0.753 & 1.1 & 6.3 & 5 & 2.86 & 3.91 & 24 & 8.6 & 17 & 2.8 \\
10 & 0.75 & 0.66 & 0.9 & 3.9 & 5.6 & 2.32 & 2.55 & 17 & 2.3 & 10 & 3.8 \\
11 & 2.88 & 2.69 & 1.8 & 10.3 & 4.5 & 4.92 & 3.81 & 14 & 20 & 11 & 2.1 \\
12 & 1.078 & 1.078 & 1.2 & 3.3 & 3.4 & 3.69 & 3.16 & 32 & 3.4 & 13 & 2.8 \\
13 & 3.3 & 2.73 & 2.7 & 10.6 & 9.1 & 3.26 & 3.85 & 18 & 3.0 & 13 & 3.2 \\
\hline
\end{tabular}

M: microtremor; t: top; b: bottom; 1D: 1D equivalent linear analysis; T: trench wall.

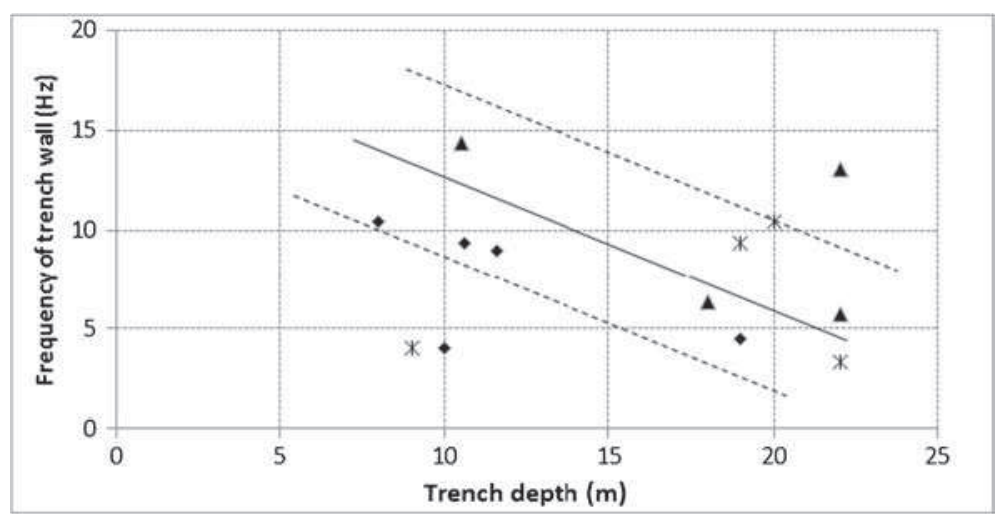

Figure 9. Scatter plot of frequency against the trench depth. Thickness of the layer affects the fundamental frequency (triangles, stars and rhombus show sands, fine-grained soils and gravels, respectively). 
with 1D analysis. The site S4 is located near the Golestan River and its path has changed over the time. From the tectonic point of view, Mashhad valley is subsiding. The land subsidence in northeast Iran were investigated by Motagh and his colleague (Motagh et al. 2007) by Interferometric Synthetic Aperture Radar (inSAR) levelling and Global Positioning System (GPS) monitoring. The annual rate of $15 \mathrm{~cm} \mathrm{yr}^{-1}$ was estimated for subsidence in northwestern part of Mashhad city. This phenomenon is caused in depositing of coarse grain sediments on fine grains of flood plain. The 1D analysis assumes that the soil layers are horizontal, parallel and infinite, and neglects the potential impacts of surface and subsurface geomorphic conditions. Based on the 1D equivalent linear analyses, the amplitude values of fundamental frequency could be categorized to three groups; 10-15 (A), 15-20 (B), > 20 (C). The sites S1, S2, $\mathrm{S} 4$ and $\mathrm{S} 11$ are classified as group $\mathrm{A}$, the sites $\mathrm{S} 3$, S5, S6, S7 and S10 are categorized as group B, and the sites S8, S9, S12 and S13 are classified as group C. In 1D equivalent linear analysis, the amplitude of fundamental frequency is affected by thickness of layers and groundwater level. Maximum amplitudes of fundamental frequency are observed at sites S8 and $\mathrm{S} 12$.

For assessing the dynamical properties of the trench wall, both 1D equivalent linear and microtremor analyses were used. In microtremor studies, floor spectral ratio (FSR) method was used to define dynamical properties of the trench wall. In 1D equivalent linear, dynamical properties of the trench wall were estimated by determining the top and bottom layers of the trenches as outcrops. The results are presented in figure 8 and table 2. Fundamental frequency of trench wall for western sites is higher than fundamental frequency of total soil profile. As mentioned, the fundamental frequency is affected by the thickness of soft sediments. Figure 9 shows the scatter plot of fundamental frequency of the trench wall against depth of trench. As seen, thickness of the layer directly influences the fundamental frequency.

The damping values obtained by FSR are presented in table 2. The maximum and minimum values of damping ratio belong to gravels and fine-grained soils, respectively. The correlations of damping ratio and frequency could not be assessed because of limited data.

\section{Conclusion}

This paper presents a quick and efficient approach by using ambient measurements to investigate the dynamic properties of ground. The microtremors were measured at top and bottom of trenches at
13 sites throughout the Mashhad city, Iran. FSR methods were used to evaluate the natural frequency and the damping ratio of the trenches wall layers. Natural frequencies of the main $\mathrm{H} / \mathrm{V}$ peak curve at the top and bottom of the excavated layers were almost similar because of the thick alluvium of Mashhad plain but the natural frequencies of the excavated layers were significantly different. The peak frequency of the excavated layers varied between 2.0 and $10.6 \mathrm{~Hz}$, and the peak amplitude ranged from 2.5 to 20.2. Damping ratio is one of the important parameters in site effect analysis, which was obtained by half power bandwidth methods in the present work. Damping ratio increased with frequency.

\section{Acknowledgements}

This research was supported by Zamin Physic Pouya Consulting Engineering Company and authors would like to thank this support. They gratefully acknowledge the Editor, Pawan Dewangan, and two anonymous reviewers for comments and suggestions that significantly improved the manuscript.

\section{References}

Apostolidis P, Raptakisa D, Roumeliotib Z and Pitilakis K 2004 Determination of S-wave velocity structure using microtremors and space method applied in Thessaloniki (Greece); Soil Dyn. Earthq. Eng. 24 49-67.

Azadi A, Javan-Doloei G, Hafezi-Moghadas N and HessamiAzar K 2009 Geological geotechnical and geophysical characteristics of the Tus Fault located north of Mashhad, north-eastern Iran; J. Earth Space Phys. 35(4) 17-34 (in Persian with English abstract).

Bakir S, Sucuoglu H and Yilmaz T 2002 An overview of local site effects and the associated building damage in Adapazari during the 17, August 1999, Izmit earthquake; Bull. Seismol. Soc. Am. 92(1) 509-526.

Borcherdt R D 1970 Effects of local geology on ground motion near San Francisco Bay; Bull. Seismol. Soc. Am. 60(1) 29-61.

EduPro Civil System Inc 1998 ProShake-Ground Response Analysis Program; EduPro Civil System Inc, Redmond, Washington.

Field E and Jacob K 1993 The theoretical response of sedimentary layers to ambient seismic noise; Geophys. Res. Lett. 20 2925-2928.

Gosar A, Rošer Šket J, Motnikar B and Zupančič P 2010 Microtremor study of site effects and soil-structure resonance in the city of Ljubljana (central Slovenia); Bull. Earthq. Eng. 8 571-592.

Hafezi Moghadas N, Ghayamghamian M R and Nikudel M R 2007 Site effect evaluation at Mashhad city seismic microzonation of Mashhad city; Project No. 5, Report of Khorasan Razavi Road and Urban Development Organization, Iran (in Persian).

Hasancebi N and Ulusay R 2006 Evaluation of site amplification and site period using different methods for an earthquake-prone settlement in western Turkey; Eng. Geol. 87 85-104. 
Ibs-von Seht M and Wohlenberg J 1999 Microtremor measurements used to map thickness of soft sediments; Bull. Seismol. Soc. Am. 89(1) 250-259.

Idriss I M 1990 Response of soft soil sites during earthquakes; In: H Bolton Seed Memorial Symposium, Berkeley, CA, BiTech, 2 273-289.

Jafari M K, Ghayamghamian M R, Davoodi M, Kamalian M and Sohrabi Bidar A 2005 Site effects of the 2003 Bam Iran; Earthq. Spectra 21(1) 125-136.

Joyner W B and Boore D M 1988. Measurement characterization and prediction of strong ground motion soil dynamics; II Proceedings of the Earthquake Engineering, pp. 27-30.

Kanai K and Tanaka T 1954 Measurement of the microtremor, I; Bull. Earthq. Res. Inst. 32 199-209.

Kanai K and Tanaka T 1961 On microtremors, VIII; Bull. Earthq. Res. Inst. 39 97-114.

Komak Panah A, Hafezi Moghaddas N, Ghayamghamian M R, Motosaka M, Jafari M K and Uromieh A 2002 Site effect classification in east-central of Iran; J. Seismol. Earthq. Eng. 4(1) 37-46.

Konno K and Ohmachi T 1998 Ground-motion characteristics estimated from spectral ratio between horizontal and vertical components of microtremor; Bull. Seismol. Soc. Am. 88(1) 228-241.

Lermo J and Chavez-Garcia F J 1994 Are microtremors useful in site response evaluation? Bull. Seismol. Soc. Am. 84 1350-1364.

Leyton F, Ruiz S, Sepúlveda S A, Contreras J P, Rebolledo S and Astroza M 2013 Microtremors' HVSR and its correlation with surface geology and damage observed after the 2010 Maule earthquake (Mw 8.8) at Talca and Curicó Central Chile; Eng. Geol. 161 26-33.

Luzón F, Al Yuncha Z, Sánchez-Sesma F J and OrtizAlemán C 2001 A numerical experiment on the horizontal-to-vertical spectral ratio in flat sedimentary basins; Pure Appl. Geophys. 158 2451-2461.

Motagh M, Djamour Y, Walter T R, Wetzel H U, Zschau J and Arabi S 2007 Land subsidence in Mashhad Valley northeast Iran: Results from InSAR levelling and GPS; Geophys. J. Int. 168(2) 518-526.

Nakamura Y 1989 A method for dynamic characteristic estimation of subsurface using microtremor on the ground surface; Quart. Report of Railway Technical Res. Inst. (RTRI) 30(1) 25-33.

Nakamura Y 2000 Clear identification of fundamental idea of Nakamura's technique and its applications; 12th World Conference on Earthquake Engineering, Auckland.

Nguyen F, Teerlynck H, Van Rompaey G, Van Camp M, Jongmans D and Camelbeeck T 2004 Use of microtremor measurement for assessing site effects in Northern Belgium - interpretation of the observed intensity during the Ms=50 June 111938 Earthquake; J. Seismol. 8(1) $41-56$.

Ohmachi T, Konno K, Endoh T and Toshinawa T 1994 Refinement and application of an estimation procedure for site natural periods using microtremor; J. Japan Soc. Civil Engineers 27 251-261 (in Japanese with English abstract).

Olsen K B and Archuleta R J 1996 Three-dimensional simulation of earthquakes on the Los Angeles fault system; Bull. Seismol. Soc. Am. 86(3) 575-596.
Rezaei K, Mumsaz N, Hejazi H, Sarraf R and Norouzi S 2012 Soil and sediments microzonation for evaluation of site effects on earthquake damages in Mobarakeh Esfahan, Iran; Open J. Geol. 2 213-228.

Seed H and Sun J I 1989 Implications of site effects in the Mexico Earthquake of Sept. 19, 1985 for earthquakeresistant design criteria in the San Francisco Bay Area of California; Earthquake Engineering Research Center, Report No. UCB/EERC-89/03, University of California, Berkeley.

Seed H B and Idriss I M 1970 Soil module and damping factors for dynamic response analysis; Report No. EERC Earthquake Engineering Research Center, University of California, Berkeley.

Seed H B, Wong R T, Idriss I M and Tokimatsu K 1986 Moduli and damping factors for dynamic analyses of cohesionless soils; J. Geotech. Eng. ASCE 112(11) 1016-1032.

SESAME 2004 Guidelines for the implementation of the $\mathrm{H} / \mathrm{V}$ spectral ratio technique on ambient vibration measurement processing and interpretation; Project WP12Deliverable D23 12.

Singh A P, Annam N and Kumar S 2014 Assessment of predominant frequencies using ambient vibration in the Kachchh region of western India: Implications for earthquake hazards; Nat. Hazards 73(3) 1291-1309.

Singh S K, Lermo J, Dominguez T, Ordaz M, Espinosa J M, Mena E and Quass R 1988 The Mexico earthquake of September 19, 1985 - A study of amplification of seismic waves in the valley of Mexico with respect to a hill zone site; Earthq. Spectra 4 653-673.

Somerville P and Graves R 1996 Site effects in the Los Angeles area during the 1994 Northridge; 11th World Conference on Earthquake Engineering, Acapulco, 23-28 June 1996, paper No. 711.

Sun J, Golesorkhi R and Seed H B 1988 Dynamic moduli and damping ratio for cohesive soils; Report No. EERC-88/15, Earthquake Engineering Research Center, University of California, Berkeley.

Teramo A, Maugeri M, Bottari A and Termini D 2005 On a quick seismic microzonation of wide areas; Pure Appl. Geophys. 162 671-682.

Tertulliani A 2000 Qualitative effects of local geology on damage pattern; Bull. Seismol. Soc. Am. 90(6) 1543-1548.

Tokeshi J C and Sugimura Y 1998 On the estimation of the natural period of the ground using simulated microtremors; Proceeding of the Second International Symposium on the Effects of Surface Geology on Seismic Motion, Yokohama Japan 2 651-664.

Walling M Y, Mohanty W K, Nath S K, Mitra S and John A 2009 Microtremor survey in Talchir India to ascertain its basin characteristics in terms of predominant frequency by Nakamura's ratio technique; Eng. Geol. 106(3-4) $123-132$

Woolery E and Street R 2002 3D near-surface soil response from H/V ambient-noise ratios; Soil Dyn. Earthq. Eng. $22865-876$.

Xun G, Wong Y L and Yifan Y 2002 Estimation of damping ratio of soil sites using microtremor; Earthq. Eng. Eng. Vib. 1(1) 45-49.

Zeng Y 1993 Theory of scattered P- and S-wave energy in a random isotropic scattering medium; Bull. Seismol. Soc. Am. 83 1264-1276. 